\title{
Memitigasi Peran Orang Tua Di Keluarga Kristen Dalam Menanggulangi Dampak Disinformasi Dari Bingkai Teologi Pentakosta
}

\author{
Kosma Manurung \\ Program Studi Magister Teologi STT Intheos Surakarta \\ kosmamanurung@sttintheos.ac.id
}

\begin{abstract}
Article
History

Submit:

March

$4^{\text {th }}, 2021$

Revised:

May

$21^{\text {st }}, 2021$

Published:

June

$11^{\text {th }}, 2021$
\end{abstract}

\begin{abstract}
Abstrak :
Masa di mana orang percaya hidup hari ini adalah sebuah masa yang ditandai dengan begitu mudahnya informasi didapat. Sayangnya tidak semua informasi itu baik, benar, dan berguna karena ada banyak informasi yang beredar di luar sana yang sengaja dibuat untuk menyebarkan kebencian, dusta, kebejatan moral, dan berbagai tindakan lainnya yang bertentangan dengan iman Kristen. Maksud dari penelitian artikel ini adalah ingin mengambarkan peran penting yang bisa dilakukan oleh orang tua di keluarga Kristen dalam menanggulangi dampak disinformasi dari bingkai teologi Pentaksosta. Dalam penelitian ini, peneliti menggunakan metode deskriptif analisis dan kajian literatur. Adapun hasil penelitian ini menawarkan empat langkah praktis yang bisa dilakukan oleh orang tua di keluarga Kristen dalam membendung disinformasi di keluarga mereka yaitu dengan melakukan tindakan proteksi berupa pengaturan dan pembatasan akses anak terhadap internet, mengadakan pendampingan, membuka ruang diskusi, dan menjadi contoh yang bisa diteladani oleh anak.

Kata Kunci: disinformasi; keluarga; keluarga kristen; pola asuh; teologi pentakosta
\end{abstract}

\section{Abstract :}

The period in which believers live today is a time marked by the ease with which information is obtained. Unfortunately not all information is good, correct, and useful because there is a lot of information circulating out there that is deliberately created to spread hatred, lies, moral depravity, and various other acts that are contrary to Christian faith. The purpose of this article's research is to illustrate the important role that parents in Christian families can play in overcoming the disinformation impact of the Pentecostal theological framework. In this study, researchers used a descriptive analysis method and literature review. The results of this study offer four practical steps that parents in Christian families can take in stemming disinformation in their families, namely by taking protective measures in the form of regulating and restricting children's access to the internet, providing assistance, opening discussion spaces, and being examples that can be followed. by the child.

Keywords: disinformation; family; christian family; parenting; pentecostal theology 


\section{Pendahuluan}

Keluarga adalah rancangan yang lahir dari hati Allah untuk menjadi sebuah wadah ilahi bagi setiap anak untuk mendapatkan pendidikan, pemeliharaan, perlindungan, kasih sayang dan perhatian. (Budiyana, 2018, p. 581) Alkitab mengambarkan bagaimana Allah begitu menaruh perhatian terhadap keluarga, Allah dengan inisiatif-Nya membentuk keluarga agar bisa berfungsi menjalankan rencanaNya dan berdampak bagi kemuliaan-Nya. (Manurung, 2020, p. 94) Kitab Kejadian melukiskan dengan sangat indah bagaimana inisiatif Allah untuk membangun sebuah keluarga, Allah dalam hikmat dan pengetahuan yang tampa tanding berkesimpulan bahwa adalah tidak baik bagi manusia untuk hidup seorang diri, manusia dalam hal ini Adam perlu penolong yang sepadan untuk memenuhi mandat yang Allah berikan baginya. Dari sini kemudian Allah menciptakan Hawa untuk menemani dan menolong Adam memenuhi mandat ilahi dan tujuan Tuhan bagi mereka waktu itu untuk beranak cucu dan bertambah banyak serta memelihara bumi. (Hannas and Rinawaty, 2019, p. 55)

Umumnya proses hidup manusia lahir, masa kanak-kanak, remaja, bertumbuh dewasa, menikah, menjadi orang tua, manula dan kembali ke Sang Pencipta. (Pono, 2018, p. 39) Dalam semua proses kehidupan itu, manusia butuh keluarga. (Subianto, 2013, p. 331) Natur normal manusia pasti lahir dalam sebuah keluarga walaupun dalam beberapa kasus misalnya anak yang tidak diinginkan atau hasil perkosaan yang mengalami namanya penolakan, tidak dilahirkan dan disambut secara normal dalam sebuah keluarga. Masa dimana orang percaya hidup saat ini ditandai dengan kemajuan tehnologi informasi yang begitu masif, setiap hari begitu banyak informasi yang dibisa diakses dengan begitu mudah oleh setiap orang tak terkecuali anak-anak mereka dengan sangat mudah mengakses berbagai macam berita maupun tontonan. (Setiawan, 2019, p. 1) Tentunya dari semua informasi yang masuk dikeluarga, tidak semua informasi itu sifatnya benar dan berguna, melainkan ada informasi yang sengaja dibuat berisi berita bohong, niat jahat, dan hal negatif lainnya yang dalam hal ini harus difilter oleh para orang tua dikeluarga Kristen dengan benar sehingga tidak merusak anak-anak dirumah. (Hartono 2018, p. 62) 
Alkitab menegaskan prinsip utama terkait dengan tanggung jawab untuk mendidik dan membesarkan anak dalam sebuah keluarga ada pada kedua orang tua. (Manalu, 2020, p. 16) Kaum Pentakosta menyadari benar akan arti penting peran utama orang tua dalam mendidik dan membesarkan anak. (Purba 2018, p. 35) Kalis Stevanus menyatakan bahwa orang tua bertanggung jawab penuh dalam menjaga, memelihara, dan mendidik anak. (2018, p. 79) Senada dengan itu Yushak Soesilo juga mendukung orang tua lebih lagi memainkan peran mereka dalam hal pola asuh dan pola didik anak sehingga anak-anak ini bertumbuh mengenal dan menghidupi kebenaran Tuhan. (2016, p. 1) Itu artinya orang tua bertanggung jawab penuh dalam membentengi anak-anak mereka dari banjir informasi yang membombardir keluarga mereka setiap harinya termasuk juga memfilter dan membendung disinformasi yang bersifat merusak yang bisa saja diakses oleh anak-anak mereka. Peneliti dalam artikel ini mencoba menyuguhkan peran orang tua di keluarga Kristen dalam menanggulangi disinformasi dari bingkai teologi Pentakosta.

\section{Metodologi}

Peneliti menggunakan metode penelitian kualitatif dengan pendekatan deskriptif analitik dan kajian literatur ketika mengerjakan penelitian ini. Penelitian kualitatif dipilih karena hakekatnya yang bersifat menjelaskan makna dari suatu peristiwa atau kejadian maupun memberikan gambaran tentang sesuatu. (Zaluchu, 2020, p. 28) Pada bagian awal hasil pembahasan peneliti menganalisis beberapa bagian dari narasi Alkitab terkait dengan keluarga dan disinformasi. Hasil analisis itu kemudian peneliti jabarkan melalui pendekatan deskreptif selain itu pendekatan deskriptif juga peneliti gunakan diartikel ini dalam menjelaskan dampak disinformasi, dan gambaran terkait peran orang tua dalam menanggulangi disinformasi. Sedangkan pendekatan kajian literatur peneliti gunakan untuk mendukung, menopang, dan memperkokok pandangan-pandangan yang peneliti kemukakan baik itu dalam pembahasan narasi Alkitab tentang keluarga dan disinformasi, dampak disinformasi, maupun pada pembahasan peran orang tua dalam menanggulangi disinformasi dikeluarga. Kajian literatur yang peneliti gunakan bersumber dari artikel jurnal dan buku yang terkait dengan topik yang sedang peneliti bahas.

\section{Hasil Pembahasan}

Sabda : Jurnal Teologi - 180 


\section{Keluarga dan Disinformasi dalam Narasi Alkitab}

Alkitab adalah buku yang paling jujur yang membicarakan kehidupan manusia. (Manurung 2020a, p. 307) Hal ini terlihat dengan jelas bagaimana Alkitab menyuguhkan fakta hidup seseorang, bukan sekedar hal yang baik dari orang itu melainkan juga kelemahan dan karakter yang kurang mulia dari orang itu juga dibahas. (Hidayat, 2017, p. 285) Misalkan saja tentang Daud bagaimana Alkitab menyuguhkan cerita tentangnya dari mulai sifat baik, karakter mulia, keperkasaan dimedan perang, pahlawan gagah perkasa, kecintaan Daud pada Tuhan dan hal hebat lainnya. (Harvijanto, 2020, p. 38) Namun, Alkitab juga menulis fakta lainnya berupa kelemahan, keburukan, dan ketidak sempurnaan karakter Daud. Alkitab menceritakan bagaimana kegagalan Daud dalam menjalankan peran maupun fungsinya sebagai suami, ayah, dan kepala keluarga. Daud melakukan perzinahan yang melukai hati Allah yang berakibat teguran keras Allah atas hidup Daud. Amnon anak Daud mendapatkan informasi yang keliru berupa saran dari teman baiknya Yonadab dan gagal mengolah informasi itu, akhirnya mengambil tindakan memperkosa adiknya lain ibu Tamar yang juga anak Daud ( 2 Sam. 13:3-5). Akhirnya Amnon dibunuh oleh Absalom yang dendam karena Tamar adiknya diperkosa oleh Amnon dan merasa kesal karena ayah mereka Daud seolah menganggap ini hal biasa dan tidak menjatuhkan hukuman pada Amnon. Dikemudian hari Absalom memimpin pemberontakan besar untuk mengkudeta kepemimpinan Daud.

Jika peneliti lebih mundur kebelakang dalam lintasan waktu, kitab Taurat menarasikan bagaimana kehidupan Abraham yang saat ini dianggap sebagai bapa iman dan teladan hidup bagi tiga agama besar dunia yaitu Yadaisme, Kristen, dan Islam bukanlah sebuah perjalanan hidup dan iman yang sempurna. (Scholtz, 2017, p. 12) Dua kali Taurat mencatat Abraham karena didorong rasa takutnya akhirnya tidak mengakui Istrinya Sara sebagai pasangan hidupnya yaitu ketika berhadapan dengan Firaun raja Mesir (Kej. 12: 11-20) dan Abimelekh raja Gerar (Kej. 20:1-18). Selain itu kelemahan lainnya yang berakibat sangat buruk adalah ketidak sabaran Abraham dalam menunggu janji Tuhan sehingga demi mendapatkan seorang putra yang dijanjikan, Abraham akhirnya melakukan tindakan yang keliru dengan mendengarkan dan mempercayai informasi yang salah berupa saran sang istri Sara 
untuk tidur dengan Hagar agar mendapatkan anak. Memang Abraham mendapatkan seorang putra dari Hagar tetapi bukan putra yang kemudian ditolak oleh Allah sebagai anak yang dijanjikan Allah, bagi Allah putra Abraham adalah anak yang dijanjikan yang harus dilahirkan oleh Sara yang juga mendapatkan janji itu yaitu seorang putra yang bernama Ishak. (Rouw, 2017, p. 170)

Kisah tragis yang terjadi dalam hidup Yusuf yang membawa dia ke dalam penjara Mesir merupakan contoh yang begitu jelas bagaimana disinformasi bisa menyebabkan orang tidak berpikir berdasarkan akal sehat lagi sehingga dengan mudah melakukan tindakan-tindakan yang gegabah. (Hendi, 2017, p. 29) Hanya karena barang kali informasi itu berasal dari orang dekat dan yang disayang sehingga melupakan aspek terpenting dari obyektivitas informasi. Bahkan orang sekelas Potofar yang waktu itu merupakan kepala pengawal raja Mesir dengan mudah terbakar naik pitam oleh disinformasi yang sengaja dibuat sang istri yang mengarang fitnah keji karena Yusuf tidak mau melayani nafsu binalnya. Informasi keliru yang didapat Potifar ini akhirnya menyebabkan orang yang tidak bersalah harus menanggung derita dimasukan kepenjara padahal kenyataannya sebenarnya bertolak belakang. (Hügel, 2013, p. 69)

Disinformasi yang masuk ke raja Darius dan kegagalannya sebagai raja mengolah informasi yang masuk menyebabkan dia harus melemparkan orang yang paling dia percayai yaitu Daniel ke gua yang berisi singa-singa yang sedang kelaparan. (Nainggolan, 2019, p. 11) Sepanjang malam Daniel harus berbagi tempat tidur dengan para singa kelaparan ini. Kalau sedikit mundur kebelakang untuk melihat dengan jelas yang melatar belakangi mengapa peraturan ini berlaku dikarenakan karena sebuah motivasi yang sengaja untuk menjebak dan menyingkirkan Daniel dari posisi pemerintahan waktu itu. (Benyamin, 2019, p. 48) Lawan-lawan politik Daniel tidak suka atas semua prestasi dan pencapaian yang Daniel lakukan. Kisah Daniel dan gua singa ini menunjukan bahwa informasi yang keliru yang masuk bisa merusak pemikiran seseorang sehingga dia mengambil tindakan yang keliru. 
Raja Ahab adalah contoh lainnya bagaimana danpak buruk disinformasi itu mempengaruhi tindakan atau keputusan seseorang. Sebagai seorang raja, Ahab seharusnya mendapatkan informasi bukan sekedar dari orang-orang yang berusaha menjilat serta menyenangkannya saja, melainkan menerima masukan dari orangorang yang atas dasar kasih dan kemurnian mengkritisi setiap tindakannya.(Manurung, 2020a, p. 129) Keempat ratus lima puluh nabi Baal dan empat ratus nabi Asyera telah begitu merusak cara berpikir dan berdampak pula pada rusaknya rohani raja Ahab (1 Raj. 18:18-19). Lebih lanjut lagi pengaruh disinformasi yang masuk ini kemudian bukan sekedar mempengaruhi kalangan istana dimana raja Ahab tinggal melainkan juga dampak disinformasi ini merambat sampai pada berubahnya cara pandang bangsa Israel secara khusus terkait dengan penyembahan mereka kepada Allah. (Munthe, 2019, p. 54)

Selain Daud dan Abraham masih banyak contoh lain yang dicatat oleh Alkitab tentang kelemaham maupun perbuatan kurang menyenangkan yang hamba-Nya lakukan. Alkitab tidak menyembunyikan segala hal negatif baik yang Daud lakukan, yang Abraham maupun yang hamba Tuhan lainnya lakukan dengan maksud memaparkan keberanan yang sebenar-benarnya. (Siathen, 2019, p. 44) Kalangan Pentakosta berkeyakinan teguh bahwa Alkitab juga tidak menyembunyikan disinformasi yang dialami oleh raja Abraham, Amnon yang berasal dari keluarga Daud, Potifar, raja Darius, dan raja Ahab. Selain itu, bagi kaum Pentakosta agar orang percaya melihat bahwa pahlawan iman yang dicatat dalam Alkitab bukanlah orang yang sempurna melainkan orang yang juga bergumul dalam segala bentuk kelemahan mereka dan dengan bantuan Allah akhirnya mereka keluar sebagai pemenang dan namanya ditorehkan dalam Alkitab. (Sutoyo, 2018, p. 167) Gambaran diatas menambah teguh keyakinan Pentakosta bahwa adalah fakta tak terbantahkan bagaimana Alkitab berusaha memaparkan kebenaran dengan jujur. (Manurung, 2019, p. 37)

\section{Dampak Disinformasi}

Disinformasi itu bersifat merusak dan yang dimaksudkan bersifat merusak disini adalah ketika disinformasi yang merupakan informasi yang keliru itu mempengaruhi pikiran seseorang maka langka selanjutnya yang akan menyusul 
adalah tindakan salah yang lahir dari pikiran yang keliru karena informasi yang keliru. (Bafadhal and Santoso, 2020, p. 235) Disinformasi bisa dengan mudah merusak kepercayaan yang terlah dibangun selama bertahun-tahun, apa yang Potifar lakukan pada diri Yusuf menerangkan dengan sangat gamblang bagaimana disinformasi atau informasi yang keliru ini merusak kepercayaan. Disinformasi juga merusak hubungan persaudaraan antara Amnon dan Absalom karena mendengarkan informasi berupa nasihat keliru dari Yonadab untuk memperdaya adiknya tamar, Amnon terjebak dalam pikiran dan bertindak berdasarkan informasi nasihat keliru tersebut yang akhirnya merusak bahkan menghancurkan bukan sekedar hubungan persaudaraannya saja melainkan harus dibayar dengan nyawanya. Sifat merusak dari disinformasi ini juga cukup dirasakan oleh bangsa Indonesia secara khusus beberapa tahun lalu pada saat pilkada DKI Jakarta 2017 dan pilpres 2019. Dimana pada waktu pilkada DKI 2017 ada pihak tertentu demi mencapai kemenangan mengankat dan mempolotisi isi SARA yang kemudian berujung pada dipenjaranya Basuki Tjahaya Purnama alias Ahok. (Juditha, 2017, p. 137) Begitu juga pilpres 2019 dimana disinformasi atau infomrasi yang keliru begitu meraja rela sampai disinformasi terkait presiden Jokowi yang dianggap keturunan Cina dan diisukan terkait PKI. (Sosiawan and Wibowo, 2020, p. 133) Terlihat jelas bahwa disinformasi atau informasi yang salah ini sangat bersifat merusak dan celakanya lagi ditanggan orang ataupun pihak tertentu justru dimainkan untuk keuntungan pribadi maupun golongan. (Pakpahan, 2017, p. 479)

Disinformasi pastinya bersifat menyesatkan karena ketika informasi yang keliru mempengaruhi seseorang atau sekelompok orang kemudian mereka diyakinkian oleh informasi keliru itu, langkah selanjutnya mereka pasti akan menyebar luaskan informasi yang pada kenyataannya adalah sebuah rekayasa ataupun kekeliruan, ketika disinformasi ini semakin tersebat maka akan menjadi bola salju yang semakin membesar. (Lubis, 2020, p. 79) Alkitab memberikan contoh bagaimana disinformasi ini akhirnya merusak bahkan sampai merusak umat pilihan Allah sendiri. (Marbun, 2020, p. 1) Apa yang nabi-nabi palsu dalam hal ini informasi palsu yang diberikan oleh keempat ratus lima puluh nabi Baal dan keempar ratus nabi 
Asyera kepada raja Ahab akhirnya bukan sekedar merusak pikirannya sehingga dia tersesat dan menjauh dari Allah Israel tetapi juga apa yang Ahab sebagai raja Israel waktu itu, diikuti juga oleh rakyat Israel (1 Raj. 18:18). Disinformasi yang raja Ahab dapat dari para nabi yang disekelilingnya yang Alkitab cap nabi palsu ini akhirnya menyebabkan bangsa Israel ikut tersesat juga. Disinformasi dari berita yang menyesatkan juga pernah dialami oleh bangsa ini beberapa tahun lalu dimana waktu itu setelah pilpres yang diikuti oleh dua pasang kandidat, beberapa jam setelah suara dihitung berdasarkan perhitungan cepat masing-masing pihak menyatakan diri adalah pemenang. Bahkan pihak yang kemudian hari dinyatakan kalah oleh KPU, pada waktu itu beberapa jam setelah suara dihitung mengaku dengan keyakinan penuh memenangkan suara pemilihan dengan persentase yang meyakinkan dan tentunya kemenangan dari informasi keliru ini diikuti ucapan syukur serta rasa bahagia dari para pendukungnya. (Rozi and Sulistyawati, 2019, p. 1)

Dampak lainnya dari disinformasi yang peneliti lihat adalah disinformasi ini bersifat memecah belah, maksudnya disini membuat hubungan persahabatan putus, hubungan keluarga rusak, saling tidak percaya antara rekan, bahkan dalam tingkatan tertentu bisa memecah belah dan merusak persatuan dan kesatuan bangsa. (Suyanto et al., 2018, p. 52) Abraham dimasa tuanya merasakan benar dampak dari mengkuti saran keliru Sara agar tidur dengan pembantunya Hagar, karena dimasa tuanya Abraham akhirnya harus mengusir Hagar dan juga Ismael yang dalam hal ini merupakan anaknya. Banyak contoh masa kini bagaimana akhirnya karena disinformasi akhirnya mengoyak dan memecah belah hubungan pertemanan, persaudaraan, bahkan persatuan bangsa. (Sutantohadi, 2018, p. 1) Melanjutkan kisah setelah pilpres 2019, bagaimana pendukung pihak yang dinyatakan kalah oleh KPU tidak terima dan mulai melakukan tindakan-tindakan yang tidak terpuji. Syukurnya aksi yang mengarah ke anarki itu bisa diredam oleh aparat keamanan dan dengan dukungan oleh pimpinan dari pihak yang ikut pilpres yang walaupun kalah namun bisa menerima kekalahan itu dengan sikap dewasa dan menyarankan para pendukungnya tidak melakukan perbuatan yang melanggar hukum dan meminta untuk menjaga ketertiban bersama. (Sirait, 2020, p. 179) 
Pembiaran yang berkelanjutan terhadap disinformasi akan menjadi bencana, bencana disini bisa bersifat pribadi terhadap orang-orang tertentu juga bisa berdampak yang lebih luas tentunya. (Palupi, 2020, p. 1) Yusuf merasakan benar bencana yang diakibatkan oleh disinformasi yang diterima Potifar yang kemudian menyebabkan dirinya harus mendekap dalam penjara selama waktu tertentu. Nabi Daniel juga mengalami bencana mendatanginya karena disinformasi yang masuk kepada raja Darius, sehingga memaksa rasa untuk mengelurkan keputusan yang menyebabkan nabi Daniel harus tidur ditengah singa-singa yang kelaparan. Akibat yang lebih besar tentu dirasakan oleh keluarga raja Daud, akibat Amnon yang mengikuti nasehat informasi yang keliru dani Yonadab akhirnya melahirkan bencana berupa kematian Amnon dan pemberontakan Absalom. Sejarah mencatat banyak genosida juga terjadi karena disinformasi berupa memberikan informasi keliru dan secara terorganisir menghasut kelompok tertentu untuk memusnahkan kelompok lainnya. (Herlina and Lokananta, 2018, p. 100)

Hal paling menakutkan dari disinformasi kalau dibiarkan berkelanjutan dan tidak ada niat baik untuk segera mengatasinya dengan benar adalah bisa berakibat datangnya kutuk Tuhan. (Handayani, 2019, p. 1) Kasus raja Ahab menjadi contoh sempurna bagaimana kutuk Tuhan berlaku atas suatu bangsa karena pengaruh disinformasi yang mempengaruhi seorang raja dan terealisasi dalam tindakan nyata bahkan tindakan ini sampai mengkontaminasi seluruh negeri dengan penyembahan berhala. Kalau mundur lebih kebelakang, narasi kitab Kejadian melukiskan dengan jelas akibat disinformasi yang masuk pada keluarga pertama yang dicatat Alkitab yaitu Adam dan Hawa, bagaimana oleh informasi yang keliru keluarga ini akhirnya terpengaruh memakan buah pengetahuan dan akhirnya mendatangkan kutuk Tuhan. (Hannas and Rinawaty, 2019, p. 55)

Kutuk Tuhan adalah hal yang sangat menakutkan bagi setiap orang, normalnya tidak ada manusia yang mau hidup dalam kutuk Tuhan. (Wijaya, 2016, p. 109) Perjanjian Baru memberikan solusi ilahi bagaimana orang percaya bisa menjauhkan diri dari kutuk Tuhan yaitu memohon anugerah dan belas kasihan Allah melalui Tuhan Yesus Kristus. (Setiawan and Yulianingsih, 2019, p. 227) Arrington sebagai 
seorang teolog Pentakosta dalam bukunya Doktrin Kristen Presfektif Pentakosta menyatakan bahwa inti iman para penganut Pentakosta adalah hubungan pribadi dengan Yesus Kristus. (Arrington 2020, p. 161) Maksudnya disini untuk hidup dalam anugerah dan kasih Allah dalam pandangan Pentaksota orang harus secara pribadi meminta Tuhan Yesus mengampuni setiap pelanggaran, kejahatan, dan dosa mereka serta berusaha membangun hubungan pribadi dengan Tuhan. (Pranoto, 2017, p. 81) Mengingat begitu burunya dampak yang bisa ditimbulkan oleh disinformasi ini yang bukan hanya sekedar merusak, menyesatkan, memecah belah, bencana, hingga mendatangkan kutuk Tuhan bagi keluarga orang percaya untuk itu dalam pembahasan selanjutnya peneliti berusaha menyajikan solusi praktis yang bisa dilakukan oleh orang tua dikeluarga Kristen untuk membentengi anak-anak dan keluarga mereka dari disinformasi.

\section{Peran Orang Tua dalam Menanggulangi Disinformasi}

Era post truth dimana orang percaya hidup saat ini adalah sebuah era dimana orang lebih suka mendengarkan dan sependapat dengan apa saja yang menyenangkan telinganya tanpa mau lagi mengcross cek kebenaran dari segala bentuk informasi yang diaterima apakah informasi itu benar adanya berdasarkan fakta-fakta yang mendukungnya atau hanya sebuah rekayasa. (Parani et al., 2018, p. 152) Mirisnya dengan begitu melimpahnya informasi dan mudahnya mengakses internet, setiap harinya ada begitu banyak informasi yang berseliwiran disekitar kita yang belum tentu baik dan berguna secara khusus bagi anak-anak. (Simon, 2020, p. 93) Untuk itu pada bagian ini peneliti menawarkan empat peran yang bisa dilakukan oleh orang tua untuk menanggulangi dan membentengi anak-anak dan keluarga mereka dari disinformasi. Adapun keempat peran itu adalah sebagai berikut di bawah ini:

\section{Memproteksi}

Memproteksi yang dimaksudkan disini adalah sebuah upaya yang dilakukan oleh orang tua untuk menjaga anak-anak agar tidak terpapar dengan disinformasi. (Murni, 2017, p. 163) Internet ditangan pihak yang baik memang berguna sekali secara khusus bagi anak-anak misalnya digunakan untuk belajar online apalagi dengan diserangnya dunia termasuk negara kita oleh virus Covid 19, Internet sebagai salah 
satu tool yang sangat penting bagi keberlangsungan proses pembelajaran. (Cahyati and Kusumah, 2020, p. 152) Internet juga berguna dalam kaitan mencari informasi bahan pembelajaran untuk memperkaya proses pembelajaran semisal ruang guru, atau dalam level yang lebih tinggi semisal artikel jurnal. Namun pada kenyataannya ada pihak-pihak tertentu yang memanfaatkan internet untuk tujuan-tujuan yang salah semisal menggunakan internet untuk menebarkan kebencian, atau menggunakan internet atau media online untuk menyebarkan konten porno yang sangat merusak pola berpikir dan perilaku anak-anak dirumah.

Disinilah maksud peneliti bahwa peran orang tua harus menjaga dan juga memfilter setiap informasi-informasi yang masuk sehingga tidak merusak cara berpikir, karaktar, dan perilaku anak. (Saragih and Hasugian, 2020, p. 1) Memfilter disini juga bisa diartikan sebagai pembatasan yang dilakukan oleh orang tua. Artinya orang tua menggunakan otoritasnya untuk membatasi situs-situs yang bisa diakses, atau membatasi kapan dan dimana anak bisa menggunakan telepon selulernya, sehingga sianak tidak seenaknya bisa mengakses internet. Kaum Pentakosta sangat sepakat pentingnya orang tua untuk memproteksi anak dalam kaitan dengan disinformasi dan mendisiplinkan anak dalam segala hal termasuk juga dalam kaitan dengan mengakses internet, karena adalah tanggung jawab orang tua untuk melindungi anak dari segala bentuk kejahatan termasuk juga kejahatan media. (Stevanus, 2018, p. 79)

Pendampingan

Upaya pendampingan adalah tindakan praktis lainnya yang sifatnya harus dilakukan oleh para orang tua dalam rangka melindungi anak-anaknya dari disinformasi yang mengancam dan akan merusak pola berpikir dan perilaku mereka. (Sudaryanti, 2017, p. 506) Adalah tindakan keliru apabila orang tua merasa bahwa sudah cukup menyayangi anak apabila bisa memenuhi segala kebutuhan mereka, paling tidak sudah sanggup memenuhi kebutuhan pokok termasuk juga kebutuhan pendidikan mereka. Kekeliruan lainnya yang sering dilakukan oleh para orang tua adalah mengganti waktu kehadiran atau pendampingan mereka dengan memberikan hadiah berupa uang jajan tambahan, atau hadiah-hadiah lainnya. (Chapman and 
Campbell, 2018, p. 85) Pemberian, hadiah, kado itu baik dalam hal-hal tertentu sangat dianjurkan namun jangan pernah menggantikan kehadiran orang tua dengan uang atau sesuatu yang bisa dinilai oleh uang.

Pemberian tanpa kehadiran ibarat suap dalam hal ini uang suap yang diberikan oleh orang tua untuk mengatasi ketidak becusan mereka dalam hal pendampingan. (Chapman and Campbell, 2018, p. 87-88) Alkitab jelas menentang hal ini, kitab Amsal memberikan kesaksian bagaimana keberhasilan seorang anak tidak terlepas dari peran pendampingan pembelajaran yang dilakukan oleh orang tua. Terkait dengan pentingnya peran pendampingan orang tua untuk membentengi anak-anak mereka dari disinformasi, gereja Pentakosta yang pada dasarnya selalu mengutamakan pelayanan anak dan keluarga tentunya sangat mendorong untuk orang tua aktif berperan mengupayakan waktu sedemikian rupa untuk mendampingi anak-anak setiap harinya secara khusus ketika anak-anak ini sedang mengakses informasi dari media internet. (Purba, 2018, p. 35)

Membuka ruang diskusi

Membuka ruang diskusi adalah hal praktis lainnya yang bisa dilakukan oleh orang tua dikeluarga Kristen untuk membentengi anak-anak mereka dari serangan disinformasi. (Darmawan, 2019, p. 21) Ketika orang tua membuka ruang diskusi ada keuntungan ganda yang didapat oleh para orang tua yaitu anak-anak akan lebih terbuka karena mereka merasa keberadaan mereka diterima dan dihargai, dari sisi orang tua tentunya akan semakin mendekatkan diri dengan anak dan menambah kuat ikatan orang tua anak. (Siahaan, 2016, p. 15) Kebanyakan orang tua gagal menjadi sahabat bagi anak-anak mereka, namun ketika orang tua membuka ruang diskusi mereka sebetulnya sedang memposisikan diri menjadi sahabat dari anak. Artinya disini orang tua mengambil posisi duduk sama tinggi dan berdiri sama rendah, dalam ruang diskusi orang tua memerankan diri bukan sebagai pemegang otoritas atau pribadi otoriter melainkan memposisikan dirinya sahabat bertukar pikiran atau dalam bahasa kekinian sahabat anak untuk curhat. (Hartono, 2018, p. 62)

Mengingat peran penting dan keuntungannya untuk membendung disinformasi dan tetap menjaga keutuhan serta keharmonisan keluarga, peneliti 
sangat menganjurkan agar setiap orang tua di keluarga Kristen membuka ruang diskusi ini sebanyak mungkin di keluarga mereka. (Pasongli, 2017, p. 55) Ruang diskusi ini tidak harus formal, bisa saja ruang diskusi disini pada saat makan bersama, pada saat main atau nonton bersama, namun kalau misalnya ingin membahas hal yang agak sensitif sebaiknya pilihlah waktu dan tempat yang pas. Intinya membuka ruang diskusi oleh orang tua ini dilakukan dengan memperhatikan kearifan lokal dan nilai-nilai keluarga. (Surya Gani and Budi Lestari, 2018, p. 306) Orang tua di keluarga Pentakosta barang kali lebih sering membuka ruang diskusi dengan anak-anak mereka pada waktu ibadah keluarga yang biasanya dilakukan setiap hari atau waktu pujian penyembahan dirumah hanya materinya biasanya berkisar hal rohani. (Supatra, 2019, p. 11) Untuk itu juga disarankan keluarga di kalangan Pentakosta menambahkan topik pembahasan tidak hanya masalah rohani atau firman saja doa keluarga atau pujuan penyembahan keluarga, melainkan juga menggunakan kesempatan itu untuk membahas diskusi yang lebih terbuka misalnya hal-hal terkait dengan pergumulan yang sedang dihadapi anak dan jalan keluar untuk membentengi mereka dari disinformasi. (Stevanus, 2018, p. 79- 85)

Menjadi contoh

Menjadi contoh yang bisa dilihat untuk diteladani oleh anak-anak adalah tindakan yang paling baik yang bisa orang tua lakukan untuk membendung disinformasi. (S. Laurensius, 2018, p. 58) Karena tindakan memproteksi, mendampingi, dan membuka ruang diskusi yang orang tua upayakan akan percuma ketika para orang tua tidak menjadi contoh. (Haderani, 2018, p. 41) Misalkan saja orang tua bicara kepada anak-anaknya untuk tidak membuka situs porno, tapi malah orang tuanya ketangkap basah oleh anak sedang membuka situs porno bahkan menikmati situs itu. Contoh lainnya orang tua malah membagikan informasi atau berita hoax kepada anak-anaknya, padahal anak-anaknya entah dari mana sudah mengetahui dengan pasti bahwa berita itu adalah hoax. Inilah alasannya mengapa peneliti menyatakan bahwa orang tua harus menjadi contoh yang bisa diteladani oleh anak-anak juga dalam hal membendung dan menanggulangi disinformasi.(Prabowo, 2020, p. 162) 
Ki Hajar Dewantara bapak pendidikan bangsa berupaya membangun pendidikan di bangsa ini dengan menekankan pentingnya prinsip keteladanan. (Suwahyu, 2019, p. 192) Alkitab sangat mendorong para orang tua untuk menjadi teladan yang nantinya menjadi inspirasi dan motivasi bagi anak-anaknya untuk bertindak. (Hartono, 2018, p. 62) Di kalangan Pentakosta orang tua didorang untuk menjadi suratan Kristus yang terbuka yang bisa dibaca oleh setiap orang, dalam kaitan topik pembahasan artinya para orang tua di kalangan Pentakosta diharapkan menjadi teladan dalam setiap aspek kehidupan mereka secara khusus menjadi pribadi yang bisa diteladani dirumah. (Purba, 2018, p. 35-48)

\section{Kesimpulan}

Orang percaya saat ini hidup disebuah era dimana informasi begitu mudah diakses termasuk juga oleh anak-anak. Di sisi lain tidak semua infomrasi itu adalah informasi yang baik, benar, dan berguna baik bagi orang percaya maupun bagi anakanak karena ada informasi yang sengaja disebar yang isinya kebencian, bersifat asusila, dan hal-hal lainnya yang bertentangan dengan iman Kristen. Oleh karenanya diperlukan peran ekstra dari orang tua di keluarga Kristen untuk membendung dan menanggulangi serangan disinformasi yang menyerang anggota keluarga secara khusus yang menyerang anak-anak kita. Kegagalan orang tua dalam membendung dan menanggulangi disinformasi ini akan berakibat fatal bagi keharmonisan keluarga. Hasil penelitian ini menawarkan empat solusi praktis yang bisa dilakukan oleh para orang tua di keluarga Kristen untuk membendung disinformasi yaitu memproteksi anak-anak mereka sedemikian rupa dengan membatasi akses mereka ke internet, memfilter informasi yang boleh masuk. Para orang tua juga harus berupaya mendampingi anak-anak mereka ketika mungkin karena tugas sekolah atau alasan tertentu anak-anak ini harus mengakses internet, artinya disini ada upaya pendampingan oleh orang tua. Orang tua juga perlu membuka ruang diskusi di mana dalam diskusi ini orang tua berusaha menempatkan diri sebagai teman curhat bagi anak. Hal lainnya yang tidak boleh terabaikan adalah orang tua harus menjadi contoh yang bisa diteladani oleh anak-anak dirumah. 


\section{Daftar Pustaka}

Arrington, French L. 2020. DOKTRIN KRISTEN PERSPEKTIF PENTAKOSTA. Yogyakarta: ANDI Offset.

Bafadhal, Oemar Madri, and Anang Dwi Santoso. 2020. “MEMETAKAN PESAN HOAKS BERITA COVID-19 DI INDONESIA LINTAS KATEGORI, SUMBER, DAN JENIS DISINFORMASI." Bricolage : Jurnal Magister Ilmu Komunikasi 6(2): 235. http://journal.ubm.ac.id/ (March 2, 2021).

Benyamin, Nefry Christoffel. 2019. "DOA DAN HARAPAN AKAN ALLAH YANG MEMBEBASKAN SEBUAH TAFSIRAN POST-KOLONIAL DANIEL 9:1-27." Jurnal Abdiel: Khazanah Pemikiran Teologi, Pendidikan Agama Kristen, dan Musik Gereja 3(1): 48-59.

Budiyana, Hardi. 2018. "PERSPEKTIF ALKITAB TERHADAP KELUARGA KRISTEN." REGULA FIDEI: Jurnal Pendidikan Agama Kristen 3(2): 581-89. http:/ / ejournal.uki.ac.id/index.php/regulafidei/article/view/983.

Cahyati, Nika, and Rita Kusumah. 2020. “Peran Orang Tua Dalam Menerapkan Pembelajaran Di Rumah Saat Pandemi Covid 19." JURNAL GOLDEN AGE 4(1): 152-59. http:/ / e-journal.hamzanwadi.ac.id/index.php/jga/article/view/2203. Chapman, Gary, and Ross Campbell. 2018. The 5 Love Languages of Children. Yogyakarta: ANDI Offset. 
Darmawan, I Putu Ayub. 2019. “Pembelajaran Memorisasi Dalam Ulangan 6:6-9.” EPIGRAPHE: Jurnal Teologi dan Pelayanan Kristiani 3(1): 21. http:/ / www.stttorsina.ac.id/jurnal/index.php/epigraphe (January 7, 2021).

Haderani, Haderani. 2018. “Tinjauan Filosofis Tentang Fungsi Pendidikan Dalam Hidup Manusia." Jurnal Tarbiyah : Jurnal Ilmiah Kependidikan 7(1): 41-49. http:/ /jurnal.uin-antasari.ac.id/index.php/jtjik/article/view/2103 (January 14, 2021).

Handayani, Dwi Maria. 2019. “KORUPSI: STUDI PERBANDINGAN BERDASARKAN DUNIA TIMUR TENGAH KUNO DAN PERJANJIAN LAMA." Pengarah: Jurnal Teologi Kristen 1(1): 1-8.

Hannas, Hannas, and Rinawaty Rinawaty. 2019. “A pologetika Alkitabiah Tentang Penciptaan Alam Semesta Dan Manusia Terhadap Kosmologi Fengshui Sebagai Pendekatan Dalam Pekabaran Injil." DUNAMIS: Jurnal Teologi dan Pendidikan Kristiani 4(1): 55-74. http:/ / www.sttintheos.ac.id/ejournal/index.php/dunamis (November 15, 2020).

Hartono, Handreas. 2018. “Membentuk Karakter Kristen Pada Anak Keluarga Kristen." Kurios 2(1): 62. http://www.sttpb.ac.id/e-journal/index.php/kurios (January 12, 2021).

Harvijanto, Andri. 2020. “Progresivitas Perjanjian Daud.” Journal KERUSSO 5(1): 3846. http:/ / alkitab.sabda.org/article.php?id=8403, (February 3, 2021).

Hendi, Hendi. 2017. “Empat Peristiwa Penting Di Dalam Kehidupan Yusuf: Sebuah Kajian Terhadap Kecerdasan Yusuf." DUNAMIS: Jurnal Penelitian Teologi dan Pendidikan Kristiani 2(1): 29. http:/ / www.sttintheos.ac.id/ejournal/index.php/dunamis (November 30, 2020).

Herlina, Mira, and Arbi Cristional Lokananta. 2018. “DAMPAK INFORMASI HOAX DIMEDIA SOSIAL TERHADAP TINGKAT KONFLIK DAN SIKAP PADA REMAJA." PROMEDIA Public Relation dan Media Komunikasi 4(2): 100-113. http://journal.uta45jakarta.ac.id/index.php/kom/article/view/1257.

Hidayat, Elvin Atmaja. 2017. “Iman Di Tengah Penderitaan: Suatu Inspirasi TeologisBiblis Kristiani." MELINTAS 32(3): 285. 
http://journal.unpar.ac.id/index.php/melintas/article/view/2695 (January 28, 2021).

Hügel, Karin. 2013. “A Queer Reading of Joseph: Jewish Interpretations of the Beautiful Young Man in the Hebrew Bible." Biblische Notizen 157: 69-99. https://www.unet.univie.ac.at/ a9104666/huegelkarinarticlejoseph.html. Juditha, Christiany. 2017. "HATESPEECH in ONLINE MEDIA: JAKARTA ON ELECTION 2017." Jurnal Penelitian Komunikasi dan Opini Publik 21(2): 137-51. https://jurnal.kominfo.go.id/index.php/jpkop/article/view/1134.

Lubis, Fauziah. 2020. “Analisis Kebijakan Pengendalian Pelaku Hoax Dan Ujaran Kebencian." PERSPEKTIF 9(1): 79-86.

http://dx.doi.org/10.31289/ perspektif.v9i1.3104PERSPEKTIFAvailableonlinehtt p://ojs.uma.ac.id/index.php/perspektif (March 2, 2021).

Manalu, Evi Octavia. 2020. "Pengaruh Konseling Pranikah Terhadap Keutuhan Keluarga." ANTUSIAS Jurnal Teologi dan Pelayanan 6(1): 16-31.

https://www.sttintheos.ac.id/e-journal/index.php/antusias/article/view/303. Manurung, Kosma. 2019. “Studi Analisis Kontekstual Ajaran Karunia Nubuat Rasul Paulus Sebagai Dasar Evaluasi Kritis Terhadap Fenomena Bernubuat Di Gereja Beraliran Karismatik." DUNAMIS: Jurnal Teologi dan Pendidikan Kristiani 4(1): 3754. https://sttintheos.ac.id/e-journal/index.php/dunamis/article/view/189 (November 23, 2019).

- - - 2020a. "Ketubim Dan Nubuat." Pengarah: Jurnal Teologi Kristen 2(2): 129-40. https:/ /10.0.141.174/ pengarah.v2i2.24 (November 4, 2020).

- - - . 2020b. "MEMAKNAI KEMARAHAN ALLAH DARI SUDUT PANDANG TEOLOGI PENTAKOSTA DI ERA POST MODERN." VISIO DEI: JURNAL TEOLOGI KRISTEN 2(2): 307-28.

http://jurnal.sttstarslub.ac.id/index.php/js/article/view/162. - - . 2020c. "Taurat Dan Nubuat Palsu: Kajian Sudut Pandang Taurat Terhadap Nubuat Palsu." Jurnal Teologi Berita Hidup 2(2): 94-109. http:/ / www.stttawangmangu.ac.id/e-journal/index.php/fidei/article/view/4. (February 23, 2021). 
Marbun, Pardomuan. 2020. “Konsep Dosa Dalam Perjanjian Lama Dan

Hubungannya Dengan Konsep Perjanjian." CARAKA: Jurnal Teologi Biblika dan Praktika 1(1): 1-16. https:/ / ojs.sttibc.ac.id/index.php/ibc/article/view/9

(November 19, 2020).

Munthe, Eben. 2019. “Implikasi Penggunaan 'El'Dan 'YHWH' Dalam Kekristenan Masa Kini." KURIOS (Jurnal Teologi dan Pendidikan Agama Kristen) 5(1): 54-73.

Murni, Sri. 2017. “Optimalisasi Pengawasan Orang Tua Terhadap Bahaya Pelecehan Seksual Pada Anak Di Era Digital." KOLOKIUM: Jurnal Pendidikan Luar Sekolah 5(2): 163-67. http:/ / kolokium.ppj.unp.ac.id/ (January 5, 2021).

Nainggolan, Bartolomeus Diaz. 2019. “ANALISIS AJARAN KITAB DANIEL PASAL 4 PENGAKUAN RAJA NEBUKADNEZAR TENTANG KUASA ALLAH DANIEL." JURNAL KOINONIA 11(2): 11-21.

https://jurnal.unai.edu/index.php/koinonia/article/view/2350/1708.

Pakpahan, Roida. 2017. “ANALISIS FENOMENA HOAX DIBERBAGAI MEDIA

SOSIAL DAN CARA MENANGGULANGI HOAX." Konferensi Nasional Ilmu Sosial dan Teknologi 1(1): 479-84.

https://seminar.bsi.ac.id/knist/index.php/UnivBSI/article/view/184.

Palupi, Muncar Tyas. 2020. “HOAX: PEMANFAATANNYA SEBAGAI BAHAN EDUKASI DI ERA LITERASI DIGITAL DALAM PEMBENTUKAN KARAKTER GENERASI MUDA." Jurnal Skripta 6(1): 1-12.

https://journal.upy.ac.id/index.php/skripta/article/view/645.

Parani, Rizaldi, Astrid Pramesuari, Daffa Muhammad Maldiva, and Edlyn Felicia. 2018. “Mempertanyakan Kembali Bhinneka Tunggal Ika Di Era Post Truth Melalui Media Sosial." LONTAR: Jurnal Ilmu Komunikasi 6(2): 152. https:/ / ejurnal.lppmunsera.org/index.php/LONTAR/article/view/953 (March 4, 2021). Pasongli, Ifonny. 2017. “Triangulasi Cinta, Keharmonisan Keluarga Dan Kesiapan Menikah Pada Dewasa Muda Yang Berpacaran." BIOPSIKOSOSIAL JURNAL ILMIAH PSIKOLOGI 2(1): 55-64.

https://publikasi.mercubuana.ac.id/index.php/biopsikososial/article/view/21 30. 
PONO, MEFIBOSED RADJAH. 2018. “MEMAHAMI MAKNA RELASI DAN KEBERADAAN MANUSIA DALAM FILM ‘HER' Berdasarkan Perspektif Filsafat Fenomenologi Emmanuel Levinas." KENOSIS: Jurnal Kajian Teologi 4(1): 39-56. http:/ / e-journal.iaknambon.ac.id/index.php/KNS/article/view/50 (November 16, 2020).

Prabowo, Wisnu. 2020. “Peran Elkana Dan Hana Terhadap Masa Kecil Samuel: Tahap Awal Mencetak Pemimpin Kristen." EDULEAD: Journal of Christian Education and Leadership 1(2): 162-79.

Pranoto, Minggus Minarto. 2017. “KESEMBUHAN, PENEBUSAN, DAN KEBAIKAN ALLAH DALAM TEOLOGI PENTAKOSTAL." Jurnal Abdiel: Khazanah Pemikiran Teologi, Pendidikan Agama Kristen, dan Musik Gereja 1(01): 81-98. doi: https://doi.org/10.37368/ja.v1i01.88 (April 28, 2020).

Purba, Junita. 2018. “Peranan Orangtua Kristen Dalam Membina Kepribadian Remaja/Pemuda Gereja Pentakosta Indonesia Lorong Tujuh." DIDACHE Jurnal Pendidikan dan Teologi Pentakosta 1(1): 35-48. http:/ / ejournal.sttrenatus.ac.id/index.php/didache/article/view/11/0.

Rouw, Julian Frank. 2017. “Kajian Konseptual Tentang Pemilihan Allah Dalam Roma 9." Evangelikal: Jurnal Teologi Injili dan Pembinaan Warga Jemaat 1(2): 170. http:/ /journal.sttsimpson.ac.id/index.php/EJTIISSN:2548-7868 (January 19, 2021).

Rozi, Faizal Nur, and Dwi Harini Sulistyawati. 2019. “KLASIFIKASI BERITA HOAX PILPRES MENGGUNAKAN METODE MODIFIED K-NEAREST NEIGHBOR DAN PEMBOBOTAN MENGGUNAKAN TF-IDF." KONVERGENSI 15(1). http://jurnal.untag-sby.ac.id/index.php/KONVERGENSI/article/view/2828 (March 2, 2021).

S, Laurensius Arliman. 2018. “Perlindungan Hukum Bagi Anak Dalam Perspektif Pancasila Dan Bela Negara." UNIFIKASI : Jurnal Ilmu Hukum 5(1): 58. Saragih, Albet, and Johanes Waldes Hasugian. 2020. “Model Asuhan Keluarga Kristen Di Masa Pandemi Covid-19." JURNAL TERUNA BHAKTI 3(1): 1. Scholtz, Jacob J. 2017. “Israelologie: 'n Bybels-Teologiese Perspektief Oor Israel Se 
Verlede, Hede En Toekoms." In die Skriflig/In Luce Verbi 51(1): 12.

http:/ / www.indieskriflig.org.za (October 24, 2020).

Setiawan, David Eko, and Dwiati Yulianingsih. 2019. “Signifikansi Salib Bagi

Kehidupan Manusia Dalam Teologi Paulus." FIDEI: Jurnal Teologi Sistematika dan

Praktika 2(2): 227-46. http:/ / www.stt-tawangmangu.ac.id/e-

journal/index.php/fidei (November 25, 2020).

SETIAWAN, IRFAN. 2019. “Pengembangan Teknologi Informasi Dan Komunikasi

Dalam Menghadapi Era Revolusi Industri 4.0 Di Kota Pontianak." JURNAL TEKNOLOGI DAN KOMUNIKASI PEMERINTAH 1(1): 1-14.

http:/ / ejournal.ipdn.ac.id/JTKP/article/view/715.

Siahaan, Harls Evan Rianto. 2016. “Hikmat Sebagai Implikasi Pendidikan Kristiani:

Refleksi 1 Raja-Raja 3:1-15." DUNAMIS: Jurnal Penelitian Teologi dan Pendidikan

Kristiani 1(1): 15. https:/ / sttintheos.ac.id/e-

journal/index.php/dunamis/article/view/99 (November 30, 2020).

Siathen, Dixon Nixon. 2019. "Pandangan Alkitab Tentang Suap Dan Pungli."

PASCA : Jurnal Teologi dan Pendidikan Agama Kristen 15(1): 44-48.

http:/ /journal.stbi.ac.id/index.php/PSC/article/view/69 (November 29, 2020).

Simon, John Christianto. 2020. “Pendidikan Kristiani Di Era Post-Truth: Sebuah

Perenungan Hermeneutis Paul Ricoeur." DUNAMIS: Jurnal Teologi dan

Pendidikan Kristiani 5(1): 93-110. http:/ / www.sttintheos.ac.id/e-

journal/index.php/dunamis (March 4, 2021).

Sirait, Ferdinand Eskol Tiar. 2020. “Ujaran Kebencian, Hoax Dan Perilaku Memilih

(Studi Kasus Pada Pemilihan Presiden 2019 Di Indonesia)." Jurnal Penelitian

Politik 16(2): 179. www.politik.lipi.go.id (March 2, 2021).

Soesilo, Yushak. 2016. “Penggunaan Rotan Dalam Pendisiplinan Anak Menurut

Kitab Amsal 23:13-14." DUNAMIS: Jurnal Penelitian Teologi dan Pendidikan

Kristiani 1(1): 1. https:/ / sttintheos.ac.id/e-

journal/index.php/dunamis/article/view/98 (November 5, 2020).

Sosiawan, Edwi Arief, and Rudi Wibowo. 2020. “Kontestasi Berita Hoax Pemilu

Presiden Tahun 2019 Di Media Daring Dan Media Sosial." Jurnal Ilmu 
Komunikasi 17(2): 133.

http:/ /jurnal.upnyk.ac.id/index.php/komunikasi/article/view/3695 (March 2, 2021).

Stevanus, Kalis. 2018. “Tujuh Kebajikan Utama Untuk Membangun Karakter

Kristiani Anak." BIA': Jurnal Teologi dan Pendidikan Kristen Kontekstual 1(1): 79-95. http://www.jurnalbia.com/index.php/bia/article/view/21 (December 8, 2020).

Subianto, Jito. 2013. “Peran Keluarga, Sekolah, Dan Masyarakat Dalam Pembentukan Karakter Berkualitas." Edukasia : Jurnal Penelitian Pendidikan Islam 8(2): 331-54.

Sudaryanti, Sudaryanti. 2017. “MENDIDIK ANAK MENJADI MANUSIA YANG BERKARAKTER." Jurnal Pendidikan Anak 3(2): 506-17.

https://journal.uny.ac.id/index.php/jpa/article/view/11706 (January 7, 2021).

Supatra, Hendarto. 2019. “MENGENAL PENTAKOSTALISME DI INDONESIA.” Jurnal Abdiel: Khazanah Pemikiran Teologi, Pendidikan Agama Kristen, dan Musik Gereja 3(2): 11-24. doi: https:/ / doi.org/10.37368/ja.v3i2.97 (April 29, 2020).

Surya Gani, Dhesanto, and Sri Budi Lestari. 2018. “Komunikasi Dan Pola Asuh Anak Dalam Membangun Keharmonisan Pada Keluarga Tenaga Kerja Indonesia (Kasus Pada Tenaga Kerja Indonesia Di Sojomerto, Kendal)." Interaksi Online 6(4): 306-10. https://ejournal3.undip.ac.id/index.php/interaksionline/article/view/21692.

Sutantohadi, Alief. 2018. “BAHAYA BERITA HOAX DAN UJARAN KEBENCIAN PADA MEDIA SOSIAL TERHADAP TOLERANSI BERMASYARAKAT." DIKEMAS (Jurnal Pengabdian Kepada Masyarakat) 1(1): 1.

http:/ /journal.pnm.ac.id/index.php/dikemas/article/view/153 (March 2, 2021).

Sutoyo, Daniel. 2018. “Analisis Historis Terhadap Teologi Gerakan Pentakostalisme.” DUNAMIS: Jurnal Teologi dan Pendidikan Kristiani 2(2): 167. doi: https://doi.org/10.30648/dun.v2i2.171 (June 17, 2020).

Suwahyu, Irwansyah. 2019. “PENDIDIKAN KARAKTER DALAM KONSEP PEMIKIRAN PENDIDIKAN KI HAJAR DEWANTARA." INSANIA : Jurnal Pemikiran Alternatif Kependidikan 23(2): 192-204. 
http:/ / ejournal.iainpurwokerto.ac.id/index.php/insania/article/view/2290 (March 4, 2021).

Suyanto, Totok et al. 2018. “Persepsi Mahasiswa Terhadap Kemunculan Berita

Bohong Di Media Sosial." Jurnal Civics: Media Kajian Kewarganegaraan 15(1): 52

61. https:/ /journal.uny.ac.id/index.php/civics/index (March 2, 2021).

Wijaya, Hengki. 2016. “Pengenaan Manusia Baru Di Dalam Kristus: Natur, Proses,

Dan Fakta Serta Implikasi Teologis Dan Praktisnya." Jurnal Jaffray 14(1): 109.

https://ojs.sttjaffray.ac.id/JJV71/article/view/194 (December 24, 2020).

Zaluchu, Sonny Eli. 2020. “Strategi Penelitian Kualitatif Dan Kuantitatif Di Dalam

Penelitian Agama." Evangelikal: Jurnal Teologi Injili dan Pembinaan Warga Jemaat

4(1): 28. https://journal.sttsimpson.ac.id/index.php/EJTI/article/view/167

(November 23, 2020). 